\title{
Central projections of the eighth cranial nerve in lampreys
}

\author{
R. GLENN NORTHCUTT \\ Division of Biological Sciences, The University of Michigan, Ann Arbor, Mich. 48109 (U.S.A.)
}

(Accepted January 11th, 1979)

The octavolateralis area in anamniotic vertebrates constitutes the bulk of the hindbrain alar plate and is the primary target of three cranial nerves: anterior lateral line, octavius, and posterior lateral line $e^{2,3,6-8}$. There is no agreement in the literature regarding the exact rostrocaudal extent of the octavolateralis area or the nomenclature applied to this area, but most workers have recognized 3 longitudinally arranged cell groups in lampreys, cartilaginous fishes, and chondrostean fishes ${ }^{1,3,5,7,9-11,13}$. The nomenclature adopted in this study is that of Pearson ${ }^{11}$.

The octavolateralis area of lampreys consists of dorsal, medial and ventral nuclei (Figs. 1B, 2C). Rostrally, the dorsal nucleus begins immediately caudal to the cerebellar plate and continues caudally in the medulla where it ends slightly beyond the entry of the anterior lateral line nerve (Fig. 1D-E). Rostrally, the medial nucleus is continuous with the cerebellar plate, and caudally it can be traced into the medulla where it ends just rostral to the obex (Fig. 1E).

The dorsal and medial nuclei possess similar patterns of organization: both are capped laterally by the cerebellar crest - a layer of fine fibers; both consist of centrally situated neuropils supplied by the lateral line nerves (Fig. 2B); and both possess prominent periventricular cell plates (Fig. 2B, C).

Rostrally, the ventral nucleus forms the lateral edge of the cerebellar plate, and caudally it continues to obex levels (Fig. 1). The ventral nucleus is bordered laterally by the octavius nerve (Figs. 1D, 2C, D), and the cells of the ventral nucleus are more scattered than those of the dorsal and medial nuclei. The ventral nucleus contains three distinct aggregations of large neurons, termed the anterior, intermediate and posterior octavomotor nuclei (Figs. 1, 2A, C). Thus the ventral nucleus is a long column of scattered small and medium-sized cells, within which three collections of much larger neurons (the octavomotor nuclei) can be identified.

Octavius fibers have been claimed to project to only the ventral nucleus ${ }^{1}$, to both the medial and ventral nucle $i^{3}$, and primarily to the medial nucleus ${ }^{13}$. In addition, most reports claim that primary octavius fibers project to the ipsilateral cerebellum, as well as to the contralateral cerebellum by decussating in the cerebellar commissure immediately dorsal to the trochlear nucleus ${ }^{1,3,5}$ (Figs. 1A, 2A).

In an attempt to resolve these discrepancies, the central projections of the octavius nerve were determined experimentally. The membranous labyrinth in six 
transformed (12-20 cm long) specimens of lchthyomyzon unicuspis was unilaterally destroyed by aspiration or mechanical removal. Each animal was anesthetized with MS222, and a longitudinal slit was made in the roof of the otic capsule. The lips of the slit were retracted, and the membranous labyrinth was aspirated or grasped with watch maker's forceps and gently removed. The animals survived 3, 5, 7, and 12 days at $23^{\circ} \mathrm{C}$ before being reanesthetized; the brains were dissected from the neurocranium, emersed in $10 \%$ formalin, and later embedded in $25 \%$ gelatin for processing by the Wiitanen procedure ${ }^{14}$ for demonstrating degenerating axons and their terminals. All survival times were adequate to reveal degenerating octavius fibers, with 5 and 7 days being optimal. The distribution of these fibers is charted in Fig. 1.

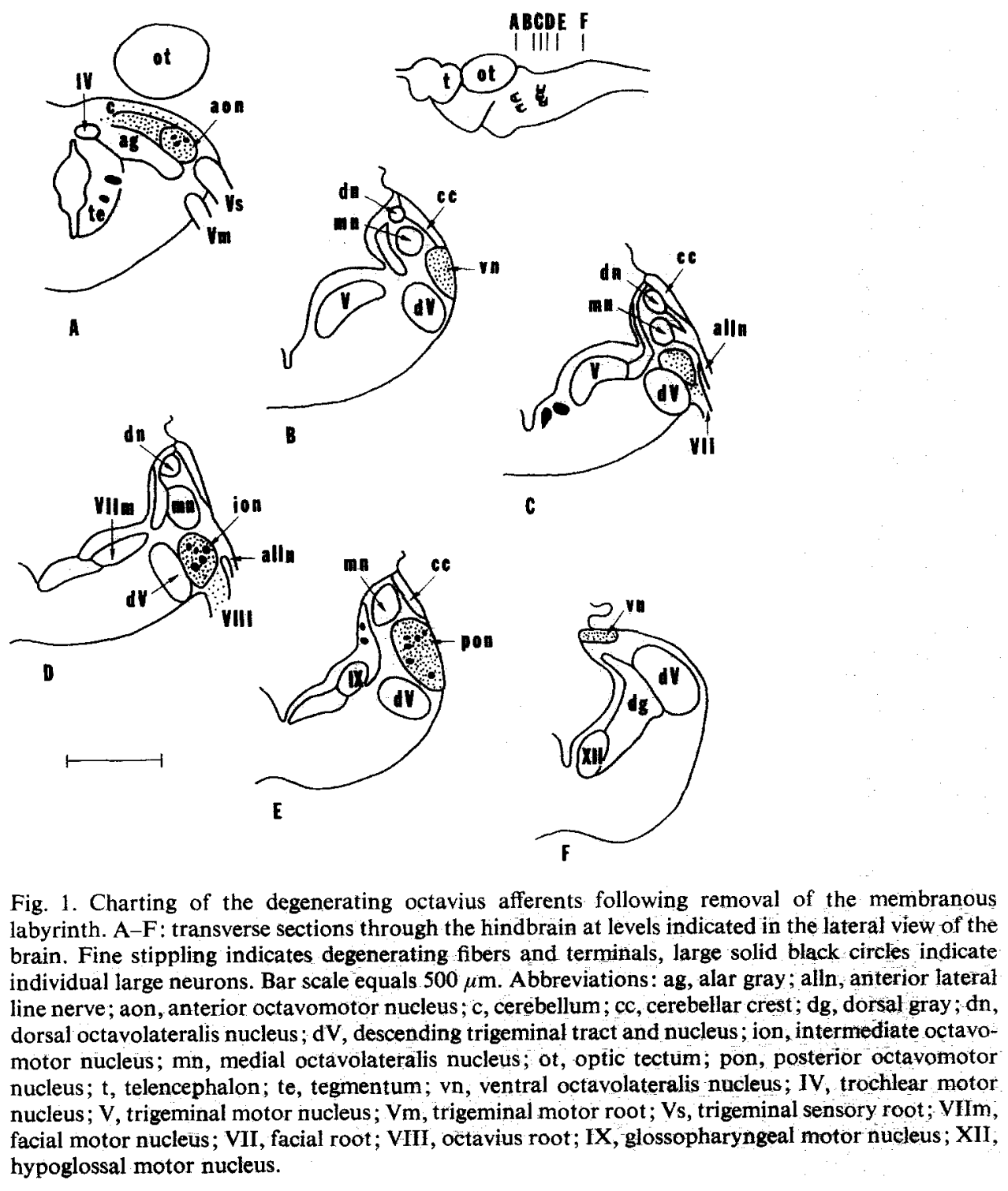


Analysis of the central projections of the octavius nerve in lampreys is complicated by the passage of two other cranial nerves medial to, or through, the otic capsule, $e^{42}$. The ganglion of the anterior lateral line nerve is located immediately ventral to the otic capsule; its entering roots pass through a foramen in the floor of the otic capsule, then course medially to the octavius ganglion through a connective tissue membrane separating the otic capsule from the lateral wall of the medulla (Fig. 2B). Thus damage to the medial wall of the otic capsule not only destroys the octavius ganglion, but also interrupts the roots of the anterior lateral line nerve. Such damage occurred in two of my cases, and degenerating fibers were traced into the dorsal and medial nuclei of the octavolateralis area via the anterior lateral line nerve.

The ganglionic mass located within the otic capsule (Fig. 2B, C) consists of octavius sensory neurons and sensory neurons of the facial nervet,12. Thus damage to the otic ganglionic mass reveals both octavius and facial afferents. In one of my cases, degenerating fibers were seen in the more ventrally located facial sensory root, as well as in the more dorsally situated octavius root. These facial fibers enter the descending trigeminal tract and course caudally in the ventrolateral sector of the descending trigeminal tract.

In 3 experimental cases, degenerating fibers were observed only in the octavius root with no involvement of the anterior lateral line or facial roots. All the degenerating octavius projections were confined to the ipsilateral hindbrain. In these cases degenerating fibers were traced into the ventral nucleus (Fig. 2D) where they form ascending and descending limbs (Fig. 1). The descending limb courses caudally through the entire extent of the ventral nucleus (Fig. 1D-F), terminating on the large neurons of the intermediate and posterior octavomotor nuclei (Fig. 1D, E). Degenerating octavius fibers continue caudally to obex levels (Fig. 1F), where the ventral nucleus ends in a dorsomedial position in the medullar wall.

The degenerating fibers of the ascending octavius limb course rostrally through the ventral nucleus (Fig. $1 \mathrm{~A}-\mathrm{C}$ ), where most of the fibers are confined to the lateral two-thirds of the nucleus. Octavius fibers continue rostrally, terminating on the cell bodies of the anterior octavomotor nucleus (Fig. 1A). At this level fibers turn medially to terminate in the cerebellum, coursing in both the molecular and cellular layers (Fig. 1A). Degenerating fibers continue to the midline but were not observed crossing to the contralateral cerebellum.

Thus the ventral and octavomotor nuclei of the octavolateralis area are the primary, if not sole, medullar targets of the primary octavius fibers. It is possible that ventrally located cells of the medial nucleus may also receive octavius afferents, as cells of the medial nucleus have dendrites that pass obliquely through the ventral nucleus ${ }^{1,5}$. However, there is no evidence that octavius fibers are a major source of afference to the medial nucleus.

Octavius fibers have been reported in larval lampreys ${ }^{13}$ projecting to the medial nucleus. However, this projection is likely due to damage to the roots of the anterior lateral line nerve which pass through the otic capsule. Such a pattern was seen in the present study in two cases which involved the lateralis system.

Degenerating octavius fibers were not traced medially to the vicinity of the 

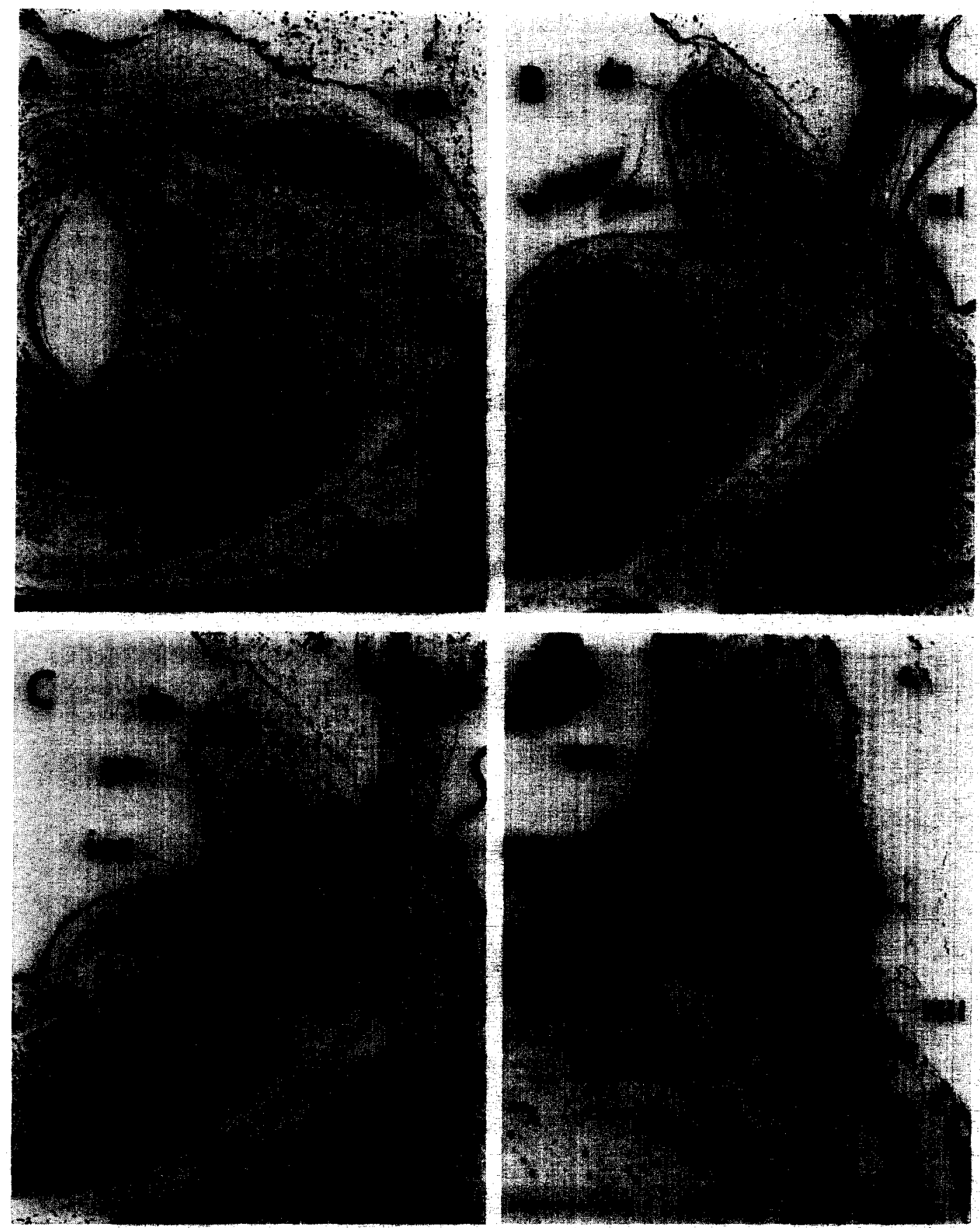

Fig. 2. Photomicrographs of lamprey hindbrain. A : transverse section through the cerebellum and isthmus at the level of the anterior octavomotor nucleus. B: transverse section through the medulla at the level of the entry of the anterior lateral line nerve. $C$ : transverse section of the octavelateralis area at the level of the entry of the octavius nerve. D: transverse section at the level of the entry of the octavius nerve showing the degenerating octavius fibers. Bar scales equal $100 \mu \mathrm{m}$. Magnifications of A through $\mathrm{C}$ are identical. Abbreviations: alln, anterior lateral line nerve; aon, anterior octavomotor nucleus; $c$, cerebellum; dn, dorsal octavolateralis nucleus; $g$, octavo-facial ganglion; ion, intermediate octavomotor nucleus; $\mathrm{ml}$, membranous labyrinth; vs, trigeminal sensory root; VIII, octavius root. 
Mauthner neuron cell body, but it is likely that connections exist, as long, laterally directed dendrites of the Mauthner neuron invade the ventral nucleus.

At present, comparable data on the primary octavius afferents exists for only one other piscine species, Amia ${ }^{7}$. In this species also the primary octavius fibers terminate in a longitudinal column of cells located ventral to the medial nucleus of the octavolateralis area, and in the medial one-third of the eminentia granularis of the cerebellum. These data suggest that the pattern seen in both lampreys and Amia may by typical of most anamniotes.

This research was supported in part by NIH Grant 1 RO1 EYO2485.

1 Heier, P., Fundamental principles in the structure of the brain; a study of the brain of Petromyzon Auviatilis, Acta anat. (Basel), 5 (Suppl. 8) (1948) 1-213.

2 Herrick, C. J., The cranial and first spinal nerves of Menidia: a contribution upon the nerve components of the bony fishes, J. comp. Neurol., 9 (1899) 153-455.

3 Johnston, J. B., The brain of Petromyzon, J. comp. Neurol., 12 (1902) 1-106.

4 Johnston, J. B., The cranial nerve components of Petromyzon, Morph. Jahrb., 34 (1905) 149-203.

5 Larsell, O., In J. Jansen, (Ed.), The Comparative Anatomy and Histology of the Cerebellum from Myxinoids through Birds, Univ. Minnesota Press, Minneapolis, 1967.

6 Maler, L., The acousticolateral area of bony fishes and its cerebellar relations, Brain Behav. Evol., 10 (1974) 130-145.

7 McCormick, C. A., Central projections of the lateralis and eighth nerves in the bowfin, Amia calva, 1978 , doctoral thesis, University of Michigan.

8 McCready, P. J. and Boord, R. L., The topography of the superficial roots and ganglia of the anterior lateral line nerve of the smooth dogfish, Mustelus canis, J. Morph., 150 (1976) 527-538.

9 Nieuwenhuys, R., Topological analysis of the brain stem of the lamprey Lampetra fluviatilis, J. comp. Neurol., 145 (1972) 165-178.

10 Nieuwenhuys, R., The brain of the lamprey in a comparative perspective, Ann. N. Y. Acad. Sci., 299 (1977) 97-145.

11 Pearson, A. A., The acoustico-lateral nervous system in fishes, J. comp. Neurol., 64 (1936) 235--273.

12 Pietschmann, V., Cyclostoma Ichthya, Handb. Zool., 6 (1933) 127-547.

13 Rubinson, K., The central distribution of VIII nerve afferents in larval Petromyzon marinus, Brain Behav. Evol., 10 (1974) 121-129.

14 Wiitanen, J. T., Selective impregnation of degenerating axons and axon terminals in the CNS of the monkey (Macaca mulatta), Brain Research, 14 (1969) 546-548. 